\title{
Corticostriatal projection neurons - dichotomous types and dichotomous functions
}

\author{
Anton Reiner ${ }^{*}$, Natalie M. Hart ${ }^{1}$, Wanlong Lei ${ }^{2 *}$ and Yunping Deng ${ }^{1}$ \\ 1 Department of Anatomy and Neurobiology, College of Medicine, The University of Tennessee Health Science Center, Memphis, TN, USA \\ 2 Department of Anatomy, Zhongshan Medical School of Sun Yat-Sen University, Guangzhou, China
}

Edited by:

Jose L. Lanciego, University of

Navarra, Spain

Reviewed by:

Ann M. Graybiel, Massachusetts Institute of Technology, USA

Elvira Galarraga, Universidad Nacional

Autónoma de México, Mexico

\section{${ }^{*}$ Correspondence:}

Anton Reiner, Department of Anatomy and Neurobiology, The University of Tennessee Health Science Center, 855 Monroe Ave., Memphis, TN 38163,

USA. e-mail: areiner@uthsc.edu, Wanlong Lei, Department of Anatomy, Zhongshan Medical School of Sun Yat-Sen University, 74 Zhongshan Rd 2, Guangzhou 510080, China.

e-mail: leiwl@mail.sysu.edu.cn
The mammalian striatum receives its main excitatory input from the two types of cortical pyramidal neurons of layer 5 of the cerebral cortex - those with only intratelencephalic connections (IT-type) and those sending their main axon to the brainstem via the pyramidal tract (PT-type). These two neurons types are present in layer 5 of all cortical regions, and thus they appear to project together to all parts of striatum. These two neuron types, however, differ genetically, morphologically, and functionally, with IT-type neurons conveying sensory and motor planning information to striatum and PT-type neurons conveying an efference copy of motor commands (for motor cortex at least). Anatomical and physiological data for rats, and more recent data for primates, indicate that these two cortical neuron types also differ in their targeting of the two main types of striatal projection neurons, with the IT-type input preferentially innervating direct pathway neurons and the PT-type input preferentially innervating indirect pathway striatal neurons. These findings have implications for understanding how the direct and indirect pathways carry out their respective roles in movement facilitation and movement suppression, and they have implications for understanding the role of corticostriatal synaptic plasticity in adaptive motor control by the basal ganglia.

Keywords: striatum, cortex, spines, synapses, projection neurons

\section{INTRODUCTION}

The so-called direct and indirect pathway model of basal ganglia function has provided a framework for understanding normal basal ganglia function, and explaining the pathophysiology of ballismus, Parkinson's disease (PD) and Huntington's disease (HD) (Albin et al., 1989; DeLong, 1990). This model, however, did not consider a number of complexities in basal ganglia organization critical to detailed understanding of its function. For example, although the cerebral cortex has a massive input to striatum, no consideration was given to how direct and indirect pathway striatal neurons might differ in their cortical input, a key issue in explaining the differing roles of these two striatal outputs in motor control. In our studies, we have found that direct and indirect pathway striatal neurons do differ in the cortical input they receive. In this paper, we review our prior findings on corticostriatal organization, present new findings, and discuss the implications of these findings for understanding the role of the basal ganglia in motor learning and movement selection.

\section{CORTICAL PROJECTIONS TO BASAL GANGLIA}

Diverse areas of cerebral cortex, including sensory, motor, and association regions, project to the striatum in all mammals studied (Kemp and Powell, 1970; Jones et al., 1977; Oka, 1980; Veening et al., 1980; Royce, 1982; Goldman-Rakic and Selemon, 1986; Tanaka, 1987; McGeorge and Faull, 1989). This input is bilateral, with an ipsilateral predominance, and it provides the striatum with the sensory and motor planning information needed for the basal ganglia to execute its role in motor control. The cortical projection is glutamatergic and ends as terminals that make asymmetric synaptic contacts, primarily with the spines of striatal projection neurons, which are by far the most abundant type of striatal neuron (Albin et al., 1989; Gerfen, 1992). The projection targets both the matrix and striosomal compartments of the striatum and is topographically organized (Kemp and Powell, 1970; Selemon and GoldmanRakic, 1985; McGeorge and Faull, 1989). Of note with respect to the role of the basal ganglia in motor control, the dorsolateral striatum receives input from the somatosensory and somatomotor cortices, and somatotopy is preserved in this input (Jones et al., 1977; Goldman-Rakic and Selemon, 1986). While the cortical input to striatum is topographically organized, any given part of striatum receives overlapping, convergent input from multiple, often related, cortical areas (Goldman-Rakic and Selemon, 1986; Brown et al., 1998; Hoffer and Alloway, 2001). Additionally, the input to striatum from any given cortical region exhibits discontinuities (Tanaka et al., 1981; Goldman-Rakic and Selemon, 1986; Flaherty and Graybiel, 1993; Alloway et al., 1998). The discontinuity in some cases represents cortical input to striosomal patches, since cortical areas receiving prominent hippocampal and amygdaloid input (e.g., prelimbic frontal cortex) preferentially project to the striosomal compartment (Gerfen, 1984; Donoghue and Herkenham, 1986). Nonetheless, the discontinuities also represent separate terminal fields within the matrix compartment of striatum - referred to as matrisomes (Flaherty and Graybiel, 1993). These latter inhomogeneities reflect the projections of different cortical layers, or different cortical neuron types, as will be discussed subsequently.

The source of the corticostriatal projection has been of interest for many years. Ramon y Cajal (1911) suggested that the corticostriatal projection arose as a collateral projection of the corticofugal 
fibers arising from pyramidal neurons of deep layer 5, as they traversed the striatum. Early retrograde labeling studies in rats, however, reported a large and widespread population of neurons in ipsilateral cortical layer 3 and in ipsilateral upper layer 5 following tracer injection into the striatum, with few of the large deep layer 5 corticobulbar and corticospinal pyramidal neurons labeled (Kitai et al., 1976; Hedreen, 1977; Hedreen and McGrath, 1977; Schwab et al., 1977; Wise and Jones, 1977; Veening et al., 1980; Arikuni and Kubota, 1986). This initially led to the view that corticostriatal input did not notably include collaterals from pyramidal tract neurons. The input from layer 3 and upper 5 was mainly thought to end in the matrix compartment, with the input to striosomes an exception arising from deep layer 5 neurons of the prelimbic cortices (Gerfen, 1989; Kincaid and Wilson, 1996). Several electrophysiological studies, however, reported that cortical neurons projecting to matrix include both pyramidal tract and non-pyramidal tract neurons. For example, Jinnai and Matsuda (1979) noted that two types of cortical neurons could be activated antidromically from striatum in cats, one type that only responded to caudate activation (60\% of corticostriatal neurons detected) and one type that responded to both caudate and pyramidal tract (PT) activation (40\% of corticostriatal neurons). While the conduction velocities of the PT-type and non-PT type were overlapping, the mean latency of antidromic activation from caudate was less for the PT-type, further supporting these as two separate corticostriatal neuron types. Similarly, Wilson (1986) showed that striatal EPSP response latencies to ipsilateral motor cortex stimulation in rats overlapped those to contralateral motor cortex stimulation, but ipsilateral responses included a short latency component that was absent in response to contralateral stimulation. Wilson interpreted this as evidence that striatum receives input from both more rapidly conducting PT-type cortical neurons as well as from more slowly conducting non-PT type cortical neurons. The conclusion that there was PT-type input to striatum was consistent with his prior evidence that stimulation of the pyramidal tract at midbrain levels evoked monosynaptic EPSPs in many striatal neurons (Wilson et al., 1982). Both Jinnai and Matsuda (1979) and Wilson (1986) noted that the PT collateral in striatum is thin and conducts much more slowly than does the main PT axon. The striatal projection of PT-type neurons of motor and somatosensory cortex via collaterals of the main descending extratelencephalic axon was confirmed anatomically in rats in other studies at that time by intracellular filling of PT-type neurons (Donoghue and Kitai, 1981; Landry et al., 1984).

\section{CORTICOSTRIATAL NEURON TYPES}

More recent studies in rats and monkeys employing cortical neuron-type specific labeling have made it clear that in each cortical region projecting to striatum at least two types of corticostriatal projection neuron can be distinguished by their connections within the telencephalon and their projections to other subcortical areas. One is the type whose main axon projects extratelencephalically (PT-type neurons) that was identified by Ramon y Cajal (1911), whereas the second projects to the basal ganglia and cortex but not outside the telencephalon (Wilson, 1987; Cowan and Wilson, 1994; Levesque et al., 1996a,b; Levesque and Parent, 1998; Reiner et al., 2003; Parent and Parent, 2006). We will refer to the latter as the intratelencephalically projecting type (IT-type). Note that not all IT-type neurons project to contralateral cortex and striatum, and this appears to be region-specific, since motor cortex but not somatosensory cortex projects heavily contralaterally. By contrast, PT-type neurons project only ipsilaterally to the striatum. In rats (Figure 1), PT-type corticostriatal neurons are typically larger than IT-type corticostriatal neurons and mainly found in lower cortical layer 5, whereas intratelencephalically projecting corticostriatal neurons are mainly found in layer 3 and upper layer 5 (Wilson, 1987; Cowan and Wilson, 1994; Levesque et al., 1996a,b; Levesque and Parent, 1998; Reiner et al., 2003; Parent and Parent, 2006). For rats, IT-type neurons have a mean diameter of $12-13 \mu \mathrm{m}$, while PT-type have a mean diameter of 18-19 $\mu \mathrm{m}$ (Reiner et al., 2003). These neurons differ too in their dendritic arborization - PT-type neurons have a prominent apical dendrite that ascends and branches profusely in layer 1 of cortex, while IT-type neuron dendrites are more slender and the arborization in layer 1 sparser. IT-type and PT-type corticostriatal neurons possessing these same various anatomical features have recently also been demonstrated in monkeys

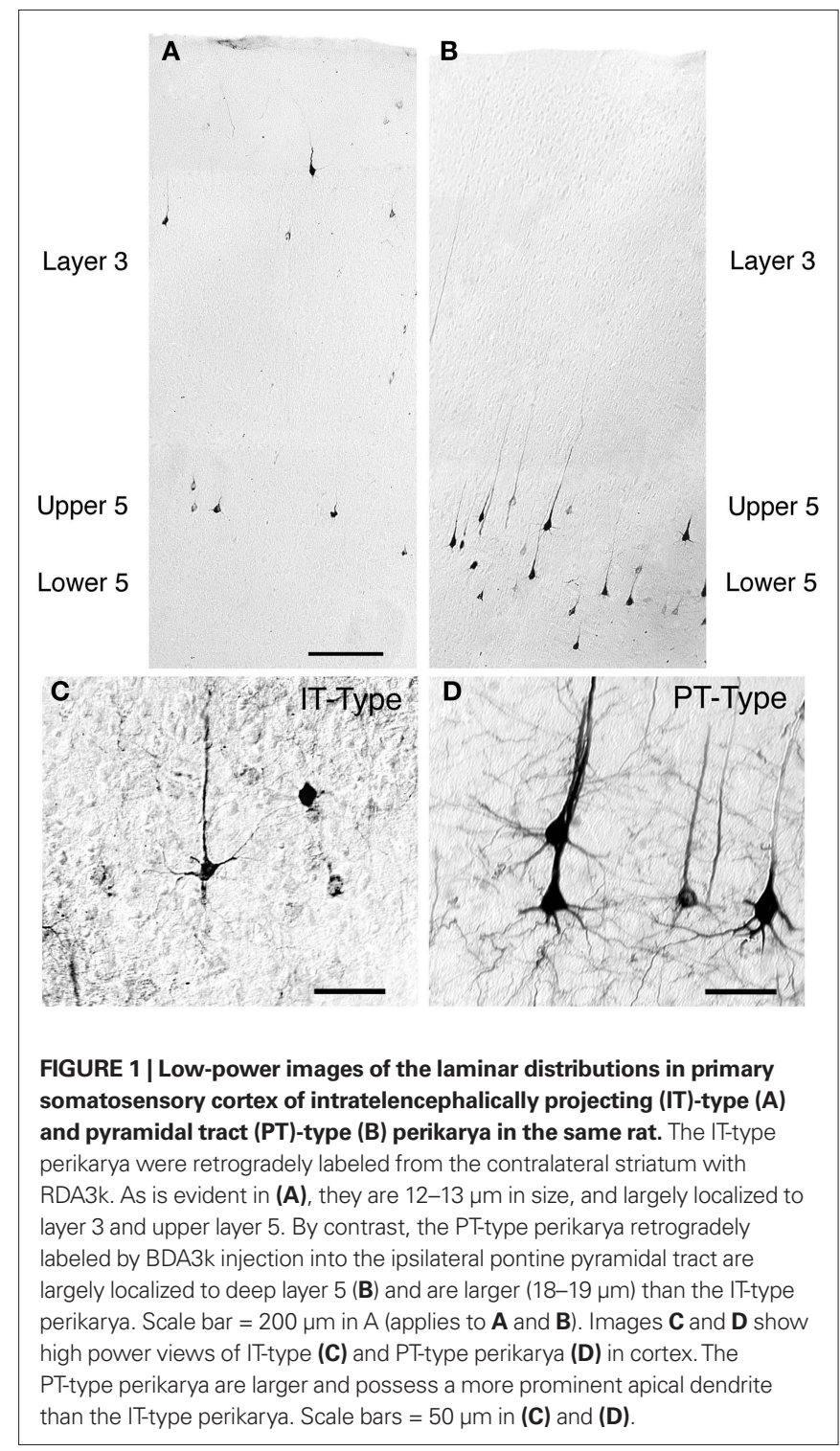


(Parent and Parent, 2006). It should be noted that layer 5 of cerebral cortex broadly consists of two neurochemically, morphologically, and physiologically distinct pyramidal neuron types matching the description of IT-type and PT-type neurons (Molnar and Cheung, 2006). Thus, IT-type and PT-type corticostriatal neurons do not merely represent a subset of layer 5 pyramidal neurons. Rather, layer 5 pyramidal neurons fall into two types - an intratelencephalically projecting type and an extratelencephalically projecting type, with each possessing a projection to striatum.

The laminar distribution of IT-type and PT-type perikarya differs slightly among cortical regions, and among species. In the somatosensory cortex in rats, the vast majority of IT-type perikarya are in layer 3 and upper layer 5, with the neurons being comparably abundant in the two (Wilson, 1987; Cowan and Wilson, 1994; Reiner et al., 2003). By contrast, in motor cortex of rats, the predominant location of IT-type perikarya is in upper layer 5, with additional IT-type perikarya being more abundant in lower layer 5 than in layer 3 . In cats, layer 3 seems to be the more prevalent location of ipsilaterally projecting IT-type neurons (Oka, 1980; Royce, 1982). Monkeys, however, appear to be more similar to rats, with upper layer 5 the predominant location of IT-type neurons revealed by ipsilateral intrastriatal retrograde tracer injection (Jones and Wise, 1977; Jones et al., 1977; Goldman-Rakic and Selemon, 1986), and in single neuron tracing studies (Parent and Parent, 2006). Using retrograde labeling from the pontine pyramidal tract to identify PT-type neurons in rats (Figure 1), we observed that about 90\% of the PT-type neurons of somatosensory cortex were in deep layer 5 , but only $65 \%$ of the PT-type neurons of motor cortex were in deep layer 5 (Reiner et al., 2003). Most of the PT-type neurons not in deep layer 5 were located in upper layer 5 in rats.

Using intracellular filling of electrophysiologically identified PT-type neurons in rats, Cowan and Wilson (1994) found that individual neurons of this type give rise to an intrastriatal arborization that consists of scattered small, dense focal clusters of terminals (about $250 \mu \mathrm{m}$ in diameter per focal cluster) spread over a 1-2-mm expanse of striatum (Cowan and Wilson, 1994). Using single axon tracing, a similar result was reported for the striatal PT-type input in monkeys (Parent and Parent, 2006). The discontinuous arborization pattern of PT-type neurons would explain why individual regions of cerebral cortex have a discontinuous projection to striatum. Moreover, part of the terminal field of each PT-type neuron of motor and somatosensory cortices has a discrete ending in dorsolateral striatum, which appears to account for the somatotopically ordered input of these cortical areas to motor striatum (Wright et al., 1999). Additionally, PT-type neurons of prelimbic cortex appear to account for the cortical input to striosomes (Kincaid and Wilson, 1996; Levesque and Parent, 1998). More recently, however, Zheng and Wilson (2001) used juxtacellular labeling to study the intrastriatal arborization of PT-type neurons of motor and cingulate cortex in rats, and reported that the PT-type neurons identified in that study possessed a broader and more diffuse striatal arborization pattern than reported in prior studies. It is uncertain whether PT-type neurons vary in their intrastriatal arborization, with cortical areas perhaps differing in the PT-type neuron varieties they possess, or if the differences observed stems from methodological differences.
IT-type corticostriatal neurons project to the ipsilateral and in many cases contralateral cortex and striatum, and neurons of the bilaterally projecting type are numerous in motor cortex (Wilson, 1987; Cowan and Wilson, 1994; Gerfen and Wilson, 1996; Kincaid and Wilson, 1996; Wright et al., 2001; Parent and Parent, 2006). In contrast to the scattered focal arborization of the PT-type neuron, the intrastriatal axon of individual IT-type neurons gives rise to an arborization that has sparse en passant terminals over a wide (about $1.5 \mathrm{~mm}$ in diameter) striatal expanse (Cowan and Wilson, 1994; Kincaid and Wilson, 1996). Recent LM studies suggest that primate striatum as well receives input from IT-type and PT-type cortical neurons possessing similar laminar location and extracortical projection patterns as in rats (Parent and Parent, 2006).

PT-type and IT-type neurons convey different signals to striatum. For example, the PT-type neurons of motor cortex in primates fire during movement and the IT-type neurons more typically fire in relation to movement planning (Bauswein et al., 1989; Turner and DeLong, 2000; Beloozerova et al., 2003). In addition, the conduction velocities of the parent PT-type axons are about three to four times more rapid than those of the parent IT-type axons (Wilson, 1986, 1987; Bauswein et al., 1989; Cowan and Wilson, 1994; Turner and DeLong, 2000). Even with the conduction velocity slowing for the thin PT-type collateral in striatum, PT-type signals reach their striatal target a few milliseconds before IT-type signals do upon their co-activation.

\section{ULTRASTRUCTURE OF CORTICAL INPUT TO STRIATUM}

Because of their differing neuronal morphologies, laminar location, and physiologies, we sought to determine if the ultrastructure of IT-type and PT-type terminals in striatum also differed (Reiner et al., 2003). IT-type intrastriatal terminals were selectively labeled anterogradely by biotinylated dextran amine (BDA)-10k injection into the contralateral motor or primary somatosensory cortex. Because IT-type but not PT-type neurons have crossed projections, BDA10k-labeled terminals in striatum contralateral to cortical injection are all IT-type. We selectively labeled PT-type terminals by BDA3k injections into pontine pyramidal tract, which yielded retrograde labeling of intrastriatal collaterals of PT-type cortical neurons. Both IT-type and PT-type terminals were seen to make asymmetric synaptic contact with spine heads and less frequently with dendrites (Figure 2). The IT-type terminals tended to be round and relatively small, and the postsynaptic density (PSD) at their axospinous contacts was rarely perforated (about 3.3\%). By contrast, PT-type terminals were more variable in shape and nearly twice as large as IT-type terminals, and the PSD at their axospinous contacts was commonly perforated (about 40\%). We recently re-measured the diameters of 240 IT-type and 220 PT-type axospinous synaptic terminals from our prior study, consistently measuring the diameter of the terminal parallel to the PSD and $0.1 \mu \mathrm{m}$ behind the presynaptic membrane. We found that the mean diameters for axospinous synaptic IT-type and PT-type terminals measured in this standardized way were 0.52 and $0.91 \mu \mathrm{m}$, respectively. Because these measurements were made in random sections that did not necessarily pass through the widest point of each terminal, they underestimate the peak size of IT-type and PT-terminals. For the IT-type terminals, this underestimate is likely to be small, since the terminals themselves are relatively small. To 

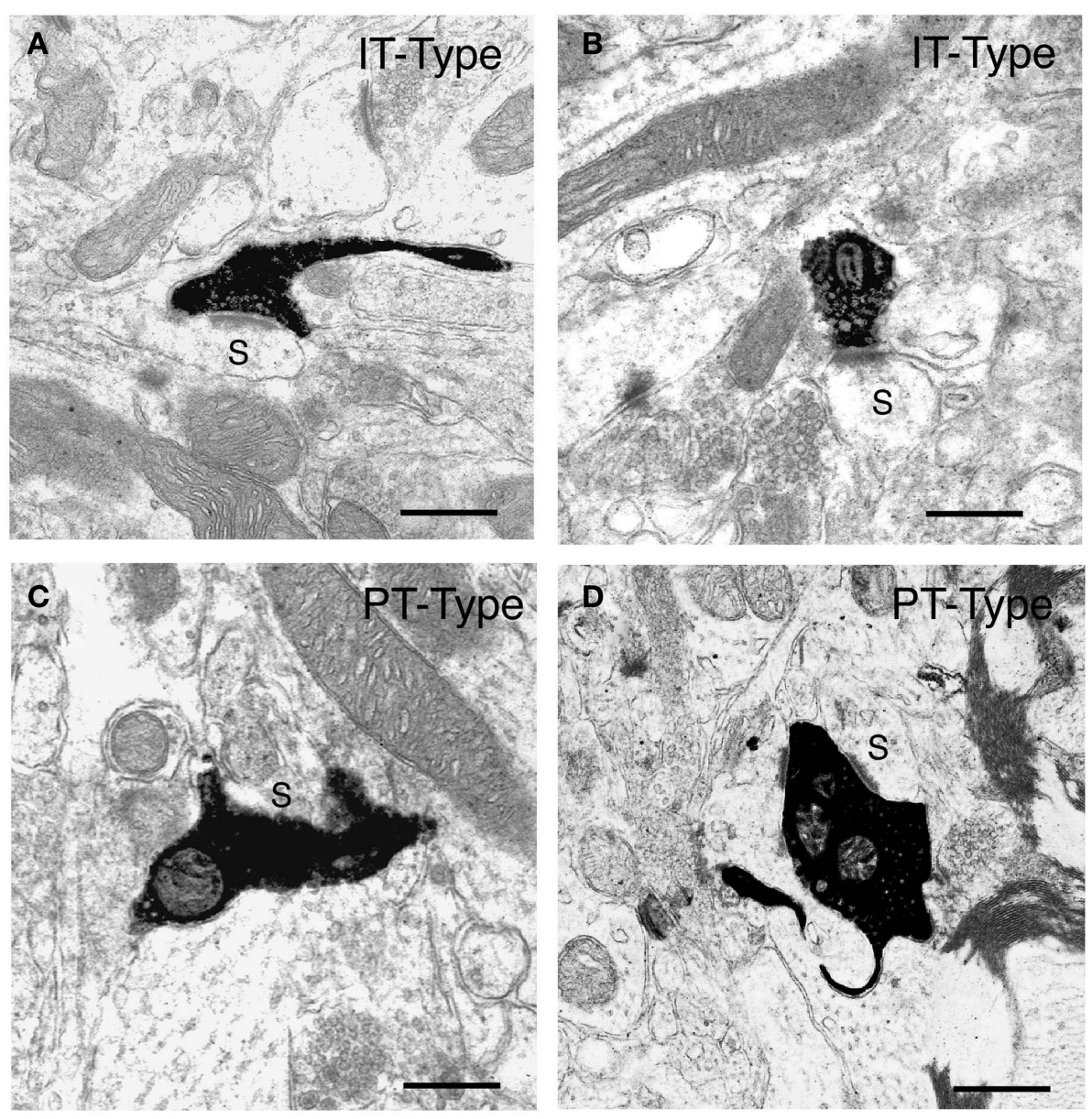

FIGURE 2 | Examples of the BDA10k-labeled intrastriatal terminals of IT-type corticostriatal neurons (A, B) and of PT-type corticostriatal neurons (C, D) at the electron microscopic level. The IT-type terminals and PT-type terminals shown each make asymmetric synaptic contact with a spine (s), as revealed by their size and the presence of spine apparatus, address the underestimate for PT-type terminals, we have analyzed several PT-type terminals in semi-serial sections, and found that their peak size is about $1 \mu \mathrm{m}$. Thus, PT-type axospinous terminals in rats labeled retrogradely collaterally from the pons are about twice the size of the IT-type axospinous terminals labeled anterogradely from contralateral cortex.

Concerns can be raised that our IT-type labeling of contralateral IT-type axons may not be representative of those that project ipsilaterally, and that the phenomenon of retrograde collateral labeling may be selective for axons that are not representative of the PT-type population as a whole. The work of Wright et al. (1999, 2001) on the intrastriatal terminals of IT-type and PT-type corticostriatal neurons of the primary somatosensory cortex of rat addresses these concerns, and is consistent with our findings. They used two anterograde pathway tracers, PHA-L and BDA, and found two distinct types of corticostriatal pathways: a non-topographic projection to the striatum with an intrastriatal arborization that was termed a "diffuse" system (Wright et al., 1999), and a topographically ordered projection that was termed the "discrete" pathway. The presumably belonging to striatal projection neurons. Note that the IT-type terminals are round, largely regular in shape, and about $0.5 \mu \mathrm{m}$ in diameter, while the PT-type terminals shown are typically large, irregular in shape, and in some cases envelop their postsynaptic target structure. Scale bars $=0.5 \mu \mathrm{m}$ in (A-D). "discrete pathway" was seen to arise as collaterals of corticofugal axons descending through the striatum, it was only ipsilateral, and it gave rise to scattered patches of dense focal innervation. The authors concluded that the diffuse system arose from the IT-type corticostriatal neurons, and the discrete system from PT-type corticostriatal neurons (Wright et al., 2001). Wright et al. (1999) noted the terminals of the diffuse pathway had a mean diameter of about $0.55 \mu \mathrm{m}$ and made asymmetric synaptic contacts with striatal projection neuron dendritic spines, and the contacts rarely possessed a perforated PSD. By contrast, the discrete system gave rise to large terminals with a mean diameter of $0.89 \mu \mathrm{m}$, and they made complex asymmetric synaptic contacts with striatal projection neuron spines that frequently possessed a perforated PSD. The findings of Wright et al. $(1999,2001)$ are thus consistent with our own, and obviate concerns that our techniques labeled atypical subsets of IT-type and PT-type terminals.

We further assessed the size of IT-type and PT-type axospinous striatal terminals by comparing their size frequency distributions to that of axospinous striatal terminals immunolabeled 
for VGLUT1. Cortical projection neurons use the vesicular glutamate transporter VGLUT1 for packaging glutamate in synaptic vesicles, while excitatory thalamic neurons use VGLUT2 (Fremeau et al., 2001, 2004; Herzog et al., 2001; Varoqui et al., 2002; Fujiyama et al., 2004). Thus, VGLUT1 is a marker of corticostriatal terminals, and VGLUT2 a marker of thalamostriatal terminals (Raju et al., 2006; Lacey et al., 2007). Using the same approach for measurement as in the case of our IT-type and PT-type axospinous endings in rats, we studied 423 VGLUT1 immunolabeled axospinous terminals in rats. Counts of random striatal fields indicated that about $70 \%$ of axospinous synaptic terminals immunolabeled for VGLUT1 and are thus corticostriatal. We also found that about $90 \%$ of VGLUT1+ terminals synapsed on spines and the remainder on dendrites. Combining the IT-type and PT-type size frequency distributions in a 1:1 ratio gave an approximate, but not exact, match to the VGLUT1 size frequency distribution. Using curve-fitting with SPSS software to more rigorously compare the size frequency distributions of IT-type and PT-type axospinous terminals to VGLUT1 axospinous terminals in rat, we found that a 58\% IT-type and $42 \%$ PT-type frequency combined to give the best fit to the VGLUT1 size frequency distribution (Figure 3A).

Thus, IT-type and PT-type axospinous terminals in rat dorsolateral striatum appear to occur in about a 3:2 ratio. Note, however, that this analysis suggests that our methods for labeling IT-type terminals were biased slightly toward smaller terminals, and that we did miss about $5 \%$ of IT-type terminals, which were in the $0.5 \mu \mathrm{m}$ size range. Similarly, our PT-type terminal labeling was slightly biased toward larger terminals, and we missed about 5\% of PT-type terminals, which were in the $0.7 \mu \mathrm{m}$ size range. If we correct for this by adjusting the IT-type and PT-type distributions to sum to match the VGLUT1 distribution (Figure 3B), with no change in their relative frequencies, then the mean predicted IT-size is $0.547 \mu \mathrm{m}$ and the mean predicted PT-size is $0.862 \mu \mathrm{m}$, which

\section{A Size Frequency Distribution for IT+PT vs VGLUT1 Axospinous Terminals}

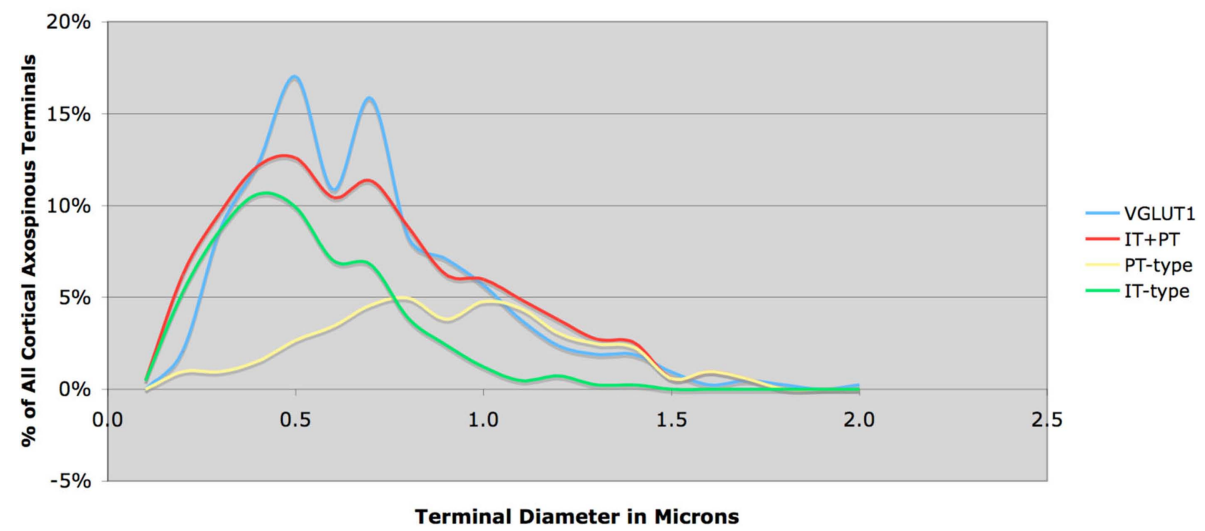

B PT and IT Size Frequency Distributions Adjusted as per VGLUT1

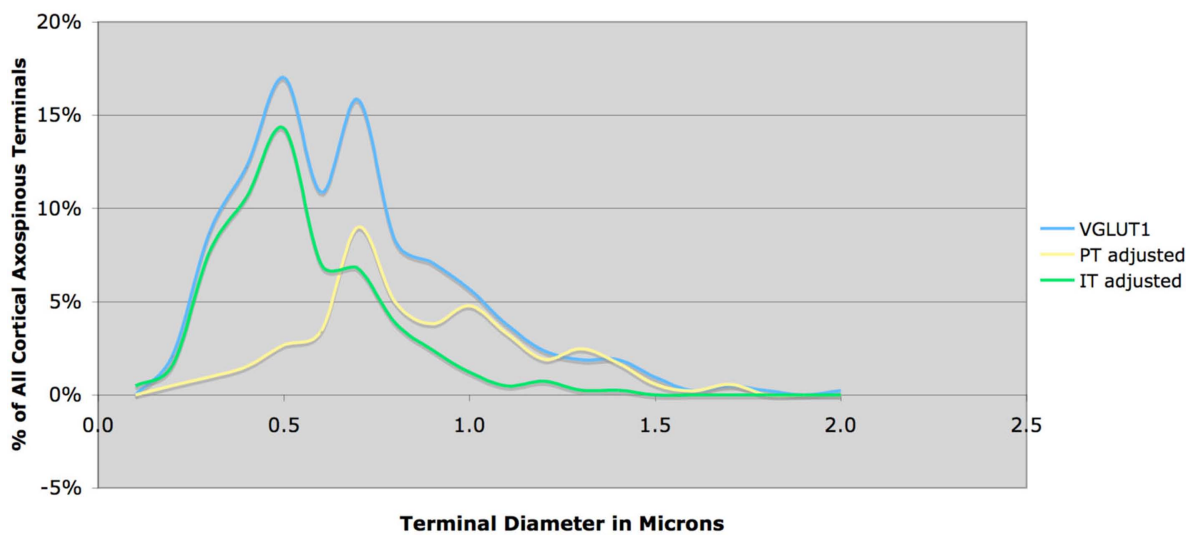

FIGURE 3 | Size frequency distribution of VGLUT1+ corticostriatal axospinous terminals in rat, compared to the measured size frequency distributions for IT-type and PT-type axospinous terminals in striatum, with IT-terminals graphed as $58 \%$ and PT-type $42 \%$ of all corticostriatal axospinous terminals (A). Note that the IT-type and PT-type distributions sum to closely approximate the VGLUT1 distribution, but there is a short fall in IT-type and PT-type terminals at 0.5 and $0.7 \mu \mathrm{m}$, respectively. In image (B), we have corrected for this shortfall, by adjusting the IT-type and PT-type distributions slightly to fit the VGLUT1 distribution, again with the IT-terminals graphed as $58 \%$ and the PT-type $42 \%$ of all corticostriatal axospinous terminals. 
yet more closely matches the sizes for these in Wright et al. (1999, 2001), and is thus more likely to accurately represent their size frequency distributions.

Recent LM studies suggest that PT-type corticostriatal terminals are larger than IT-type in monkeys as well (Parent and Parent, 2006). We have examined this issue in more detail at the EM level. We injected rhodamine dextran amine (RDA) into motor cortex and examined corticostriatal terminals in contralateral striatum (Reiner et al., 2008). As IT but not PT terminals in monkeys as well possess a contralateral striatal projection, the RDA-labeled contralateral M1 terminals were exclusively IT-type. The RDA+ IT-type axospinous synaptic terminals had a mean diameter of $0.62 \mu \mathrm{m}$, and tended to be rounded (Figure 4). To characterize all corticostriatal terminals, we examined striatum in tissue that had been immunolabeled for VGLUT1. We found that 74\% of VGLUT1+ corticostriatal terminals ended on spines (151 VGLUT1 axospinous terminals), and included two subpopulations by size and morphology. One type had a peak size of about $0.7 \mu \mathrm{m}$, and formed simple round terminals, and thus resembled the RDA+ IT-type terminals (Figure 4). The second type had a peak size of about 1.4-1.5 $\mu \mathrm{m}$. As true of PT-type terminals in rats, these larger VGLUT1+ terminals often enveloped the postsynaptic spine and the PSD of the contacted spine was often perforated. These results suggest that, as in rats, IT-type and PT-type corticostriatal axospinous terminals are morphologically distinct. Subtracting the IT-type size frequency distribution from the VGLUT1 size frequency distribution to derive the IT-type and

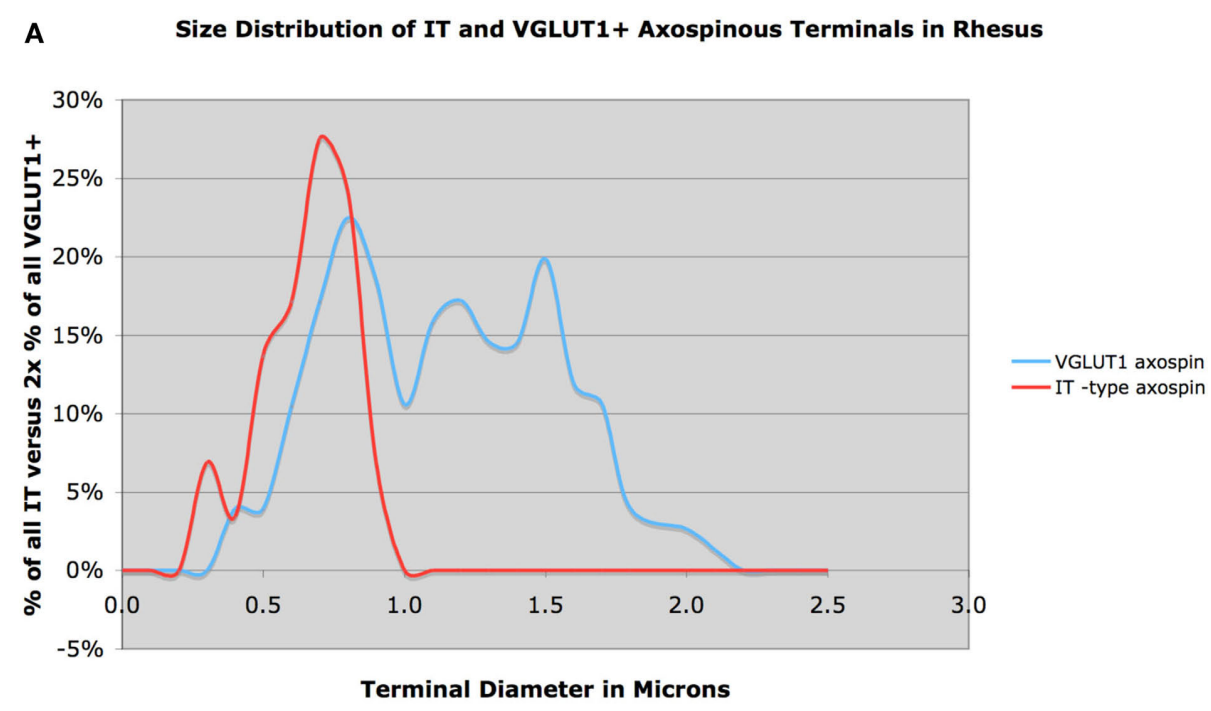

B Derived Size Frequency Distribution of IT and PT Axospinous Terminals

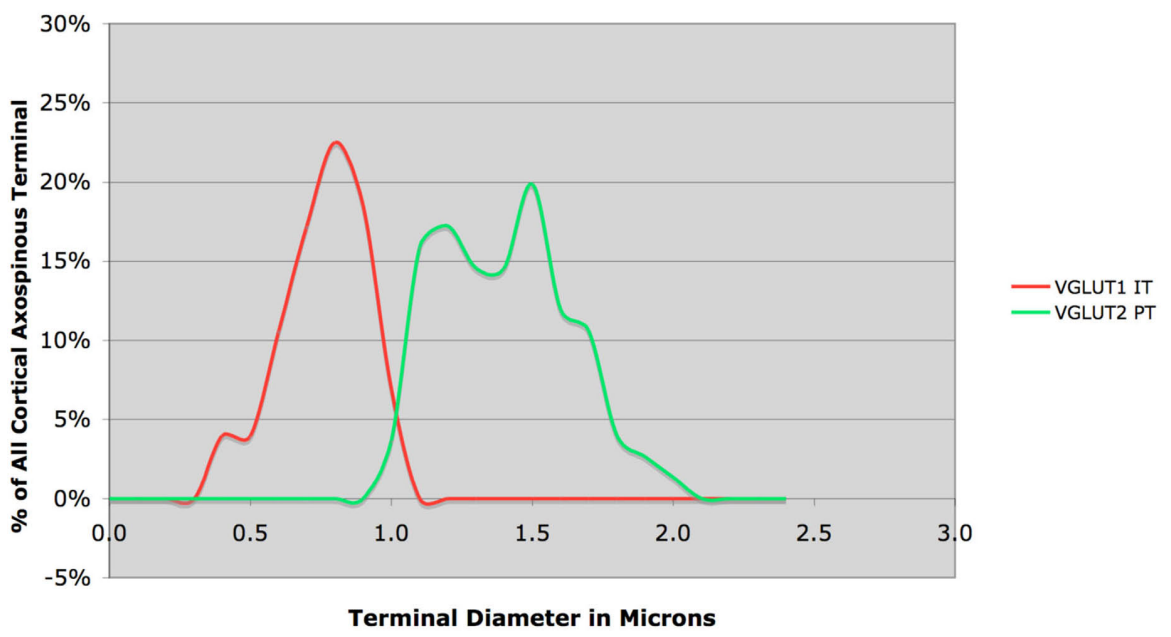

FIGURE 4 | Graph (A) shows the size frequency distribution of VGLUT1 + corticostriatal axospinous terminals (blue) in rhesus monkey, compared to the size frequency distributions for IT-type axospinous terminals (red) in striatum. Note that the IT-type distribution largely coincides with the VGLUT1 peak at about $0.7 \mu \mathrm{m}$. Graph (B) shows the inferred size frequency distributions of IT-type (red) and PT-type axospinous terminals (green) in rhesus monkey (B), derived from the relationship of IT-type terminals to VGLUT1 terminals shown in (A). 
PT-type distributions, our preliminary results suggest that IT-type account for $42 \%$ of VGLUT1 axospinous terminals in monkeys and are $0.76 \mu \mathrm{m}$ in size, and that $58 \%$ of VGLUT1+axospinous endings are PT-type and are 1.40 in mean size.

\section{DIFFERENTIAL INPUT OF CORTEX TO STRIATAL NEURONS PROJECTION NEURONS OF STRIATAL MATRIX}

We have assessed if the two types of corticostriatal neurons project differentially to the D2 receptor-rich enkephalinergic indirect pathway striato-GPe neurons and the D1 receptor-rich substance $\mathrm{P}$ (SP)-containing direct pathway striato-GPi/SNr neurons. Since axospinous IT-type terminals differ from PT-type in size, we examined in rats if axospinous synaptic terminals differed in size on these two striatal projection neuron types. We identified direct pathway neurons either by BDA3k retrograde labeling from the substantia nigra or by immunolabeling for the D1 dopamine receptor, and we identified indirect pathway neurons by BDA3k retrograde labeling from the GPe or by immunolabeling for the D2 dopamine receptor (Lei et al., 2004). Since striato-GPi neurons in rats have a collateral in $\mathrm{SNr}$, BDA3k injection into substantia nigra yields retrograde labeling of both striato-SNr and striatoGPi neurons. We thus refer to the neurons BDA3k-labeled from substantia nigra as striato-GPi/SNr. Note that while D1+ versus D2+ neurons in striatum largely represent striato-GPi/SNr versus striato-GPe projection neurons, respectively, this labeling approach is preferential but not selective due to some colocalization of these two receptor types (Surmeier et al., 1996; Deng et al., 2006). We measured the diameter of asymmetric axospinous synaptic terminals on either striatal projection neuron type in dorsolateral striatum. The values presented here are from recent re-measurements taken parallel to the PSD and $0.1 \mu \mathrm{m}$ behind the presynaptic membrane (Deng et al., 2010), and are thus revised from those presented in Lei et al. (2004). We found that asymmetric synaptic terminals on BDA3k-labeled striato-GPi/SNr neuron spines were characteristically small $(0.54 \mu \mathrm{m}$, based on 340 terminals) and rounded (Figure 5).

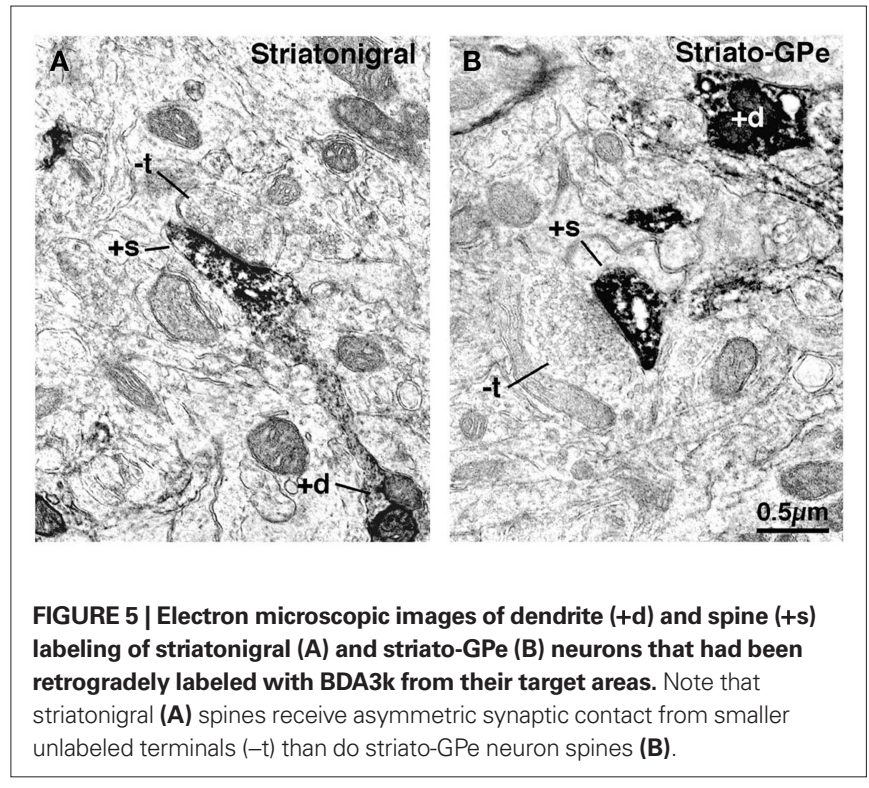

Similarly, we found that the mean size of terminals making asymmetric synaptic contact with D1+ spines was $0.55 \mu \mathrm{m}$, based on 1004 terminals. The close match in size frequency distributions for axospinous terminals on striato-GPi/SNr neurons compared to IT-type axospinous terminals indicates that IT-type greatly predominates over PT-type in the cortical input to the direct pathway neuron spines (Figure 6A). Because our VGLUT1 data suggested that our IT-type terminal labeling method may have undercounted axospinous terminals in the $0.5 \mu \mathrm{m}$ size range, we also compared the VGLUT1-adjusted IT-type axospinous terminal size frequency distribution to the size frequency distributions for axospinous terminals on striato-GPi/SNr neurons (Figure 6B). Note the yet closer fit of the adjusted IT-type distribution to the striato-GPi/ SNr distribution. Thus, IT-type terminals appear to account for the vast majority of the axospinous input to striato-GPi/SNr neurons. Determining from this approach precisely how much of the axospinous input is IT-type requires, however, also knowing the size frequency distribution of the axospinous thalamic input to striatoGPi/SNr, thought to be about $20-30 \%$ of the axospinous input (Chung et al., 1977; Smith et al., 2004). While we have found that thalamostriatal axospinous terminals immunolabeled for VGLUT2 in rats have a mean size of about $0.6 \mu \mathrm{m}$, we do not know the size frequency distribution of those ending specifically on striato$\mathrm{GPi} / \mathrm{SNr}$ neurons. In any event, these considerations suggest that striato-GPi/SNr neuron spines receive mainly IT-type input from cortex, and a less common thalamic axospinous input of largely similar size, but relatively little PT-type input from cortex (Deng et al., 2010). It will be important, however, to determine if the size frequency distribution of axospinous PT-type input to direct pathway neurons is the same as for axospinous PT-type terminals as a group. It is possible that direct pathway neuron spines receive more PT-type input than suggested by the congruence of the size distributions of axospinous IT-type terminals and axospinous terminals on direct pathway neurons, if putative PT-type input to direct pathway spines is skewed toward the smaller end of the PT-type size range. We have, however, no evidence this is the case from our prior study (Lei et al., 2004).

In contrast to direct pathway spines, asymmetric synaptic terminals on BDA3k-labeled striato-GPe neuron spines tended to be notably larger $(0.71 \mu \mathrm{m}$, based on 212 terminals $)$, irregular in shape, and in many cases associated with a perforated postsynaptic density (Deng et al., 2010). Given the sparseness of the intra-GPe collateral of SP+ striato-GPi/SNr neurons (Kawaguchi et al., 1990; $\mathrm{Wu}$ et al., 2000), and given that we previously found that only $20-25 \%$ of neurons retrogradely labeled from GPe possess direct pathway neuron neurochemistry (i.e., D1+ and ENK-negative) (Deng et al., 2006; Wang et al., 2006), the majority but not all of the striatal neurons labeled from GPe with BDA3k must have been $\mathrm{ENK}+$ striato-GPe neurons. Consistent with this, the mean size and size frequency distribution of the axospinous terminals on striato-GPe neurons cannot be accounted for by input from IT-type axospinous terminals (Figure 7A). While a prominent input from PT-type terminals better explains the size of axospinous terminals on striato-GPe neurons, the size frequency distribution of PT-type axospinous terminals, nevertheless, also does not match that for axospinous terminals on striato-GPe neurons. Several factors are likely to contribute to this. 

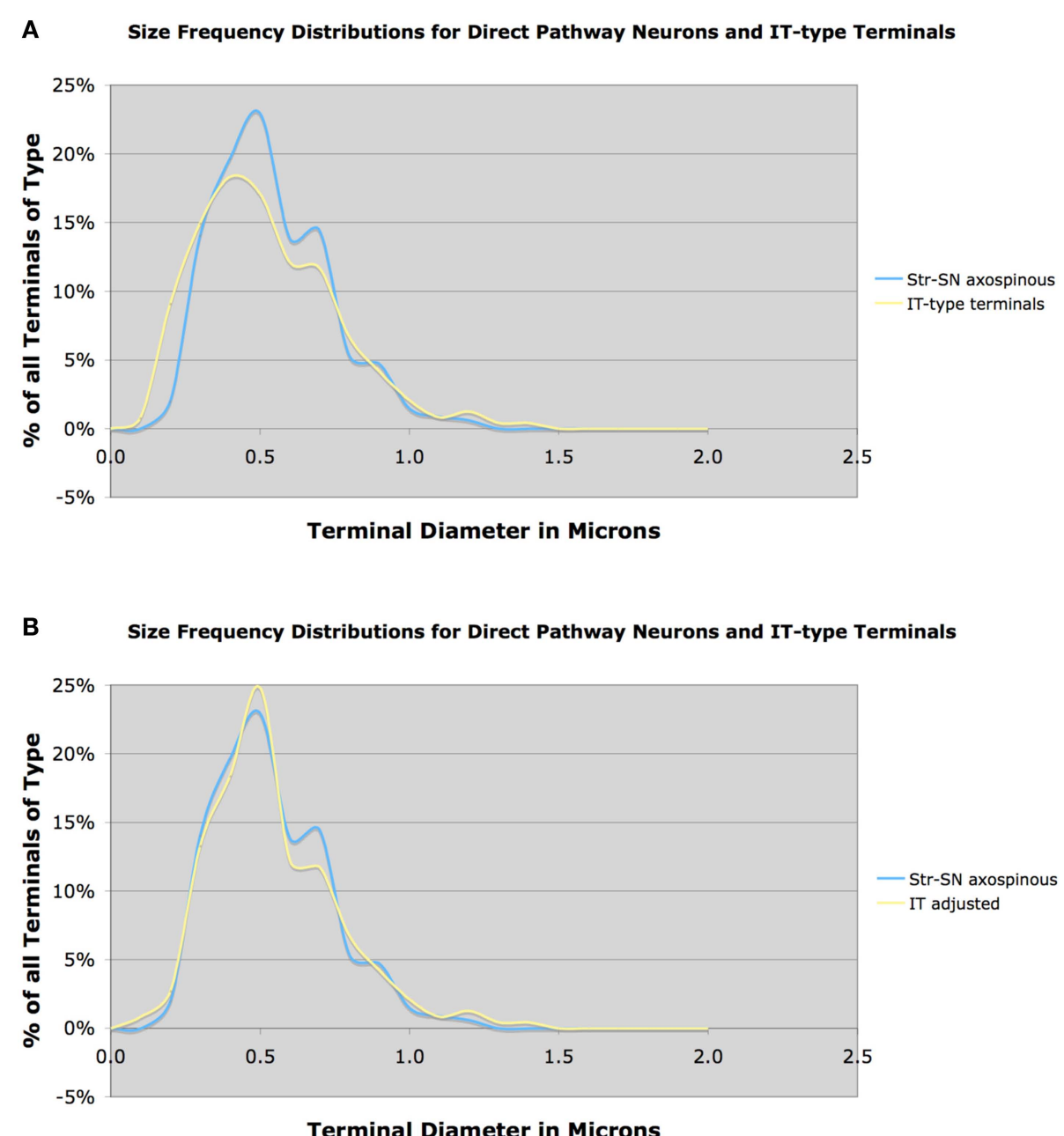

FIGURE 6 | Graph (A) shows the size frequency distribution of IT-type corticostriatal axospinous terminals in rat compared to the size frequency distribution of axospinous terminals on striato-GPi/SNr neurons neurons, while graph (B) shows the size frequency distribution of axospinous terminals on striato-GPi/SNr neurons compared to the VGLUT1-adjusted IT-type size frequency distribution shown in Figure 3B. Note that the size frequency distribution of axospinous IT-type terminals in A closely matches that of axospinous terminals on striato-GPi/SNr neurons, indicating that IT-type input (plus thalamic input of a similar size) to direct pathway neurons dominates. The fit between IT-type axospinous terminals and axospinous terminals on striato-GPi/SNr neurons is even closer for the adjusted IT-type distribution.
First, our above noted comparison of the VGLUT1 size frequency distribution to the IT-type and PT-type size frequency distributions suggests that mean PT-type axospinous size and size frequency distribution may actually have their peak at a slightly smaller size than the distribution measured from anterogradely BDA3k-labeled PT-type terminals. When we compare the VGLUT1-adjusted PT-type size distribution to the striato-GPe axospinous distribution, in fact, a much better match is obtained, with PT-type terminals seeming to account for about 75\% of the input (Figure 7B). Nonetheless, the PT-adjusted distribution does not account for the many axospinous terminals in the $0.4-0.6 \mu \mathrm{m}$ size range. These additional terminals must represent IT- and/or thalamic inputs to the striato-GPe neurons. Note also that some neurons retrogradely BDA3k-labeled from the GPe may actually be direct pathway neurons labeled via their fibers of passage, which may also account for some of the smaller terminals. The contribution of each of these factors needs to be known to determine the relative abundance of PT-type axospinous input to indirect pathway projection neurons. In any event, the mean size and size frequency distribution of the axospinous terminals on striato-GPe neurons indicate that they receive predominantly PT-type axospinous input from cortex (Deng et al., 2010). In the case of D2 immunolabeling to preferentially label indirect pathway spines, the mean size of terminals making asymmetric synaptic contact with D2+ spines was $0.65 \mu \mathrm{m}$, based on 497 terminals. Thus, this approach too indicates indirect pathway neuron spines to be the target of the large PT-type terminals. Nonetheless, the results for asymmetric terminals on $\mathrm{D} 2+$ spines is likely to understate the selectivity of PT-type input for striato-GPe neurons, since we showed that about $30 \%$ of D2+ neurons are striatonigral (Deng et al., 2006). This is likely to explain why the mean size of axospinous terminals for D2+ spines is slightly less than that for striato-GPe spines. 


\section{A Size Frequency Distributions for Striato-GPe \& IT and PT Terminals}

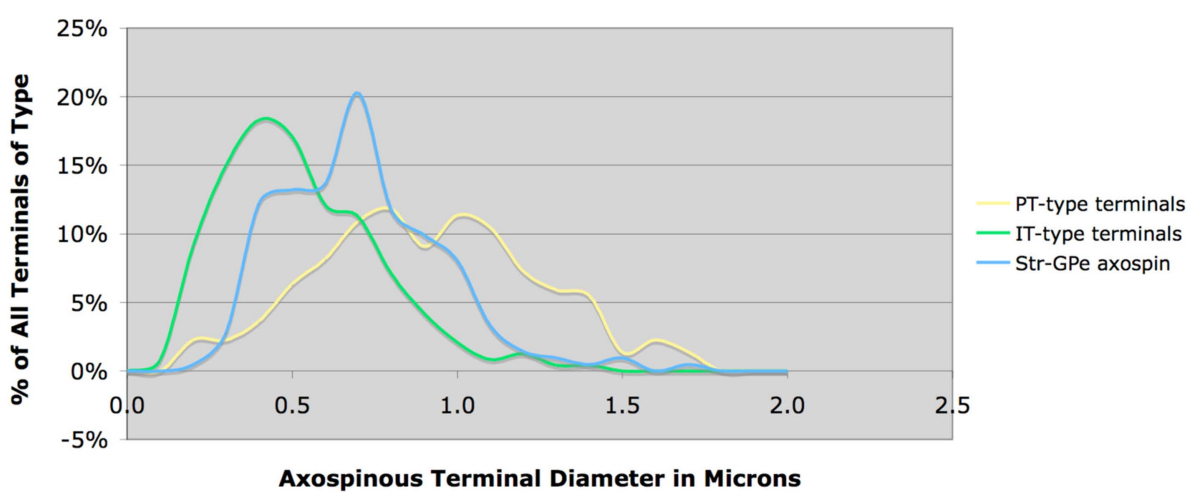

B Size Frequency Distributions for Striato-GPe \& Adjusted IT and PT Terminals

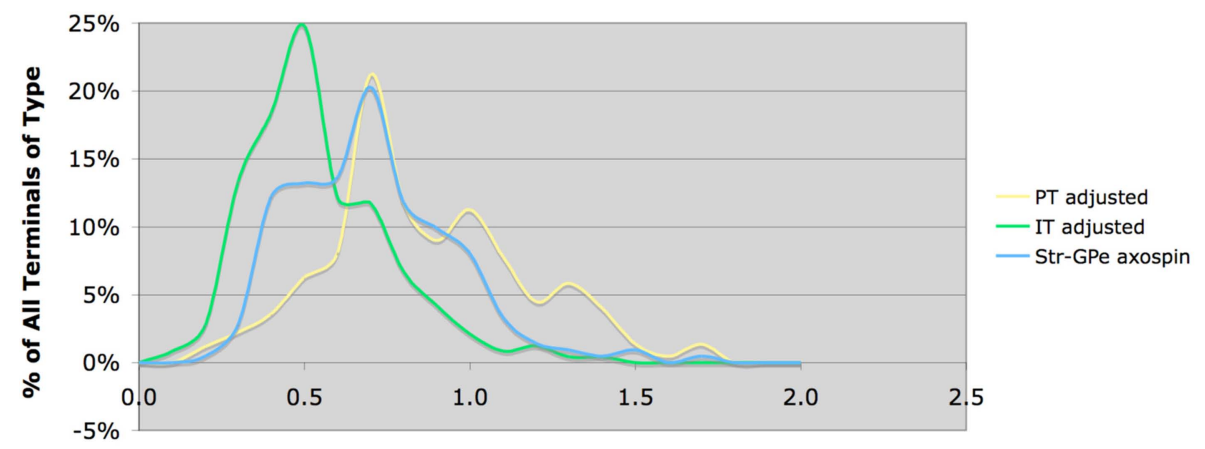

Axospinous Terminal Diameter in Microns

FIGURE 7 | Graph (A) shows the size frequency distributions for IT-type and PT-type axospinous terminals compared to that for striato-GPe neurons, while graph (B) shows the size frequency distributions for axospinous terminals on striato-GPe neurons compared to the VGLUT1-adjusted PT-type size frequency distribution shown in Figure 3B (B). Note that neither IT-type nor PT-type size distributions precisely match that for striato-GPe neurons in graph (A). The adjusted PT-type distribution does show a better fit, but still does not account for the abundance of terminals $<0.7 \mu \mathrm{m}$. This suggests that striato-GPe neurons receive a combination of IT- type and PT-type input, and the PT-type input predominates.
Similar analysis of axospinous terminals on striatonigral neurons in rhesus monkey indicated that mean axospinous terminal size on striatonigral direct pathway neurons was smaller than that on indirect pathway striato-GPe neuron spines (Figure 8A). The mean size for 81 axospinous terminals on striatonigral neurons from one rhesus monkey was $1.01 \mu \mathrm{m}$, while for 118 striato-GPe axospinous terminals from two monkeys was $1.39 \mu \mathrm{m}$. Given the size frequency distributions for IT-type and PT-type terminals evidenced in our VGLUT1 analysis, we could reach conclusions regarding the pattern of IT-type and PT-type inputs to these two striatal neuron types. The large striatonigral axospinous terminal peak at about $0.8 \mu \mathrm{m}$ clearly corresponds to the IT-type terminal peak, and indicates that IT-type input to this neuron type predominates over PT-type input. The relative thalamic versus PT-type input to this neuron type is uncertain, in part because the size frequency distribution of thalamic input is unknown for rhesus monkey.

Nonetheless, the peak at about $1.1 \mu \mathrm{m}$ is likely to represent thalamic input, since the two major PT-type peaks are greater than $1.1 \mu \mathrm{m}$. An approximately 60:30 ratio of IT-type and thalamic input seems likely for striatonigral neurons in rhesus monkey, with the small peak at $1.5 \mu \mathrm{m}$ perhaps reflecting some PT-type input. Whether striato-GPi neurons are similar to striato-SNr neurons is yet uncertain. In the case of the striato-GPe neuron input, except for the peak at $1.1 \mu \mathrm{m}$, the size frequency distribution for striato-GPe axospinous terminals is closely matched by the PT-type terminal distribution inferred from the VGLUT1 data (Figure 8B). Thus, a 70:30 ratio of PT-type input and some combination of thalamic and IT-type input to striato-GPe neurons appears reflected in these distributions.

To directly assess the cortical input to the two striatal projection neuron types, we combined BDA-labeling of IT-type or PT-type terminals with D1 or D2 immunolabeling in rats (Lei et al., 2004). We found that of all axospinous IT-type synaptic terminals labeled with BDA10k in tissue immunolabeled as well for D1, 50.9\% made synaptic contact with D1+ spines. By contrast, of all axospinous IT-type synaptic terminals labeled with BDA10k in tissue immunolabeled for D2, only $12.6 \%$ made synaptic contact with D2+ spines. Doublelabeling for PT-type terminals and D1+ (striato-GPi/SNr) or D2+ 

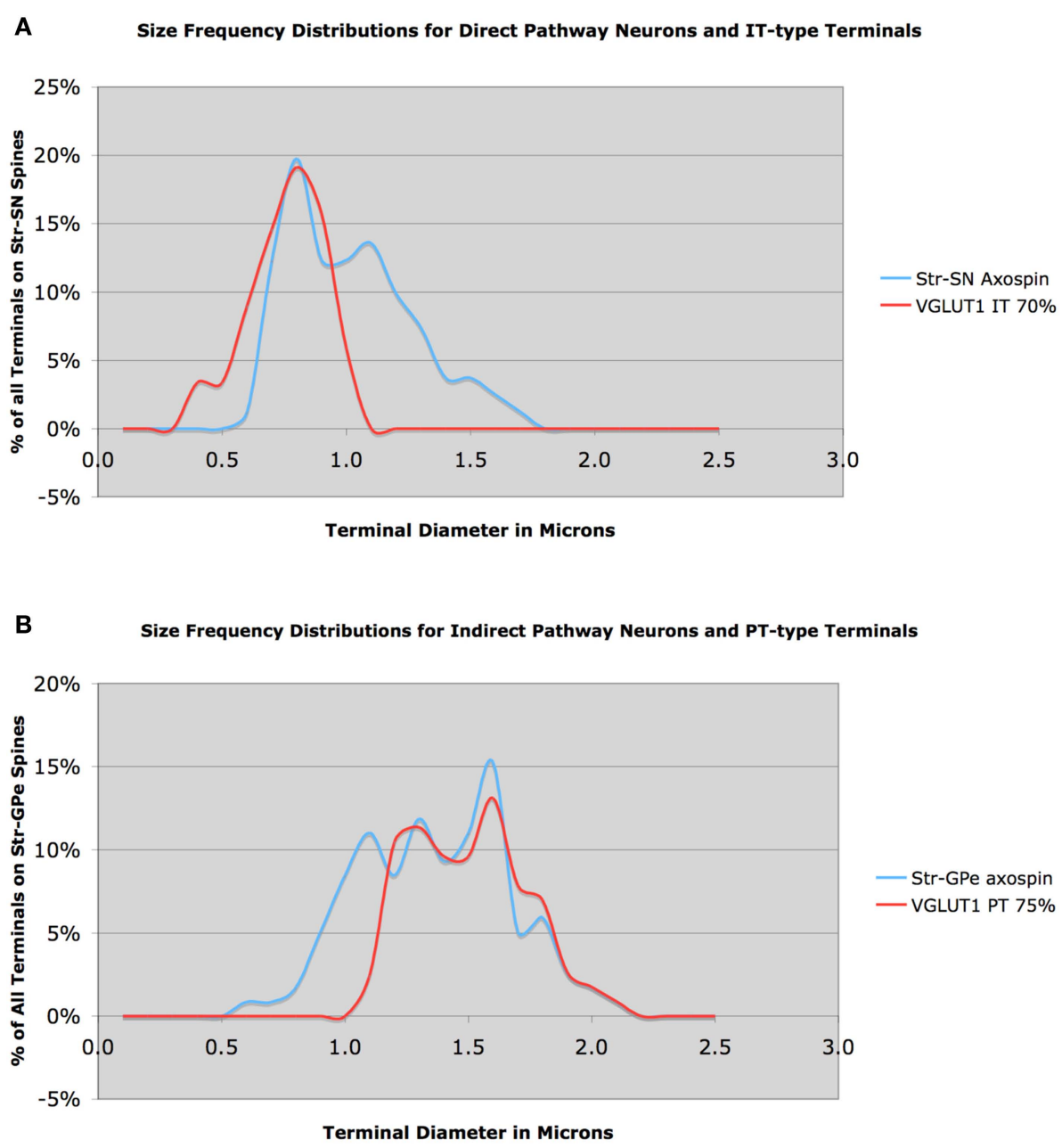

FIGURE 8 | Size frequency distribution of IT-type corticostriatal axospinous terminals in rhesus monkey compared to the size frequency distributions of axospinous terminals on striato-SNr neurons (A), and size frequency distribution of PT-type corticostriatal neurons compared to the size frequency distribution of axospinous terminals on striato-GPe neurons (B). Note that the size distribution of IT-type terminals closely matches that of terminals on striato-SNr neurons, except for a peak at $1.1 \mu \mathrm{m}$. Similarly, note that the size distribution of axospinous PT-type terminals closely matches that of axospinous terminals on striato-GPe neurons, except for a peak at $1.1 \mu \mathrm{m}$. The peak at $1.1 \mu \mathrm{m}$ is likely to include thalamic terminals.
(striato-GPe) spines showed the opposite trend - of all axospinous PT-type synaptic terminals labeled with BDA3k in tissue immunolabeled as well for D1, only $21.3 \%$ synaptically contacted D1+ spines, while of all axospinous PT-type synaptic terminals labeled with BDA3k in tissue immunolabeled for D2, 50.5\% synaptically contacted D2+ spines. Thus, these differences as well, which are statistically significant, show that IT-type terminals preferentially contact D1+ spines whereas PT-type terminals preferentially contact D2+ spines. Note, however, that these results for direct pathway neurons suggest a greater PT-type input to direct pathway neuron spines than indicated by comparisons of size frequency distributions for the different terminal types in Figure 6. Since the size frequency data clearly indicate meager PT-type input to direct pathway spines, it may be that our double-labeling resulted in some intensification of D1 immunolabeling of otherwise weakly D1+ indirect pathway neurons. The presence of IT-type terminals on D2+ spines indicated by our double-label studies is, however, consistent with our comparisons of size frequency distributions for the different terminal types in Figure 7. Nonetheless, some D2+ neurons contacted by IT-terminals in our double-label study may be direct pathway neurons with D2 receptors (Deng et al., 2006). GENSAT mice with labeling restricted to direct versus indirect pathway neurons may be ideal for resolving these uncertainties about the relative extent of IT-type versus PT-type input to the two striatal projection neuron types (Gong et al., 2007). In preliminary studies, we have found that mean axospinous synaptic terminal size on D2+ spines in D2 GENSAT mice is greater $(0.61 \mu \mathrm{m})$ than on D2-negative spines $(0.42 \mu \mathrm{m})$.

\section{PROJECTION NEURONS OF STRIOSOMES}

One study has used BDA anterograde labeling to examine the input of motor and cingulate cortex to striosomes as identified by $\mathrm{mu}$ opiate receptor (MOR) immunolabeling in rats (Wang and Pickel, 1998). They found that the BDA-labeled corticostriatal terminals ending on MOR+ spines tended to be large, and 
many exhibited a perforated postsynaptic density. Based on our measurements of the terminals shown in that study, the mean size of nine terminals making axospinous synaptic contact on MOR+ spines (thus establishing them as within striosomes) was $0.88 \mu \mathrm{m}$ and a third of these possessed perforated PSDs. These results are similar to those we have found for BDA-labeled PT-type terminals in the matrix compartment of dorsolateral striatum, and thus the results of Wang and Pickel (1998) are consistent with the view that striosomes are innervated by PT-type input ending as large axospinous terminals.

\section{PHYSIOLOGICAL EVIDENCE FOR DICHOTOMOUS CORTICAL PROJECTIONS TO STRIATAL PROJECTION NEURONS}

Our findings that IT-type terminals preferentially target direct pathway neurons and PT-type terminals preferentially target indirect pathway neurons are consistent with several electrophysiological studies. For example, indirect pathway neurons have a lower pairedpulse ratio and a higher mEPSC frequency than do direct pathway neurons in mouse striatum (Kreitzer and Malenka, 2007; Cepeda et al., 2008; Ding et al., 2008). These results suggest that excitatory synapses on indirect pathway neurons have a higher probability of transmitter release than do those on direct pathway neurons, consistent with the larger cortical terminals on the indirect pathway neurons. The larger terminals also may explain, in part, why indirect pathway striatal neurons have higher basal firing rates (Mallet et al., 2006). Cepeda et al. (2008) reported several additional findings they noted as consistent with our observation that indirect pathway neurons preferentially receive PT-type terminals and direct pathway neurons the smaller IT-type terminals: (1) D2+ but not D1+ neurons displayed prominent inward currents and large, long-lasting depolarization with increased cortical firing induced by bath application of GABAA antagonist; and (2) direct electrical activation of cortical input more readily elicited D2+ neuron responses than D1+ neuron responses at low stimulating current intensities. Our results are also consistent with the finding that activation of cortex in vivo tends to preferentially induce immediate early gene expression in ENK+ striatal neurons (Berretta et al., 1997; Parthasarathy and Graybiel, 1997), and diminished cortical activation of striatum preferentially reduces ENK expression (Uhl et al., 1988). Nonetheless, it should be emphasized that striatal projection neuron firing rate and cortical responsivity are also affected by intrinsic membrane properties and local circuit connections.

\section{PHYSIOLOGICAL EVIDENCE AGAINST DICHOTOMOUS CORTICAL PROJECTIONS TO STRIATAL PROJECTION NEURONS?}

One study reported evidence they viewed as rebutting the notion that PT-type input ends preferentially on indirect pathway type striatal neurons (Ballion et al., 2008). In one line of study, they found that the earliest ipsilateral spikes in response to the second cortical pulse in a 100 -ms pair were similar in latency for the two striatal projection neuron types (distinguished by antidromic activation from nigra). In a second approach, they found that the two striatal projection neuron types responded equally commonly to the second pulse in a $100-\mathrm{ms}$ pair delivered to contralateral cortex. Since neither outcome matched their simple prediction for a dichotomous projection of IT-type and PT-type neurons to striatum from Lei et al. (2004), Ballion et al. (2008) concluded that
IT-type input did not preferentially end on direct pathway neurons but rather ended equally on both direct and indirect pathway neurons, and PT-type input was meager to indirect pathway neurons as well as to direct pathway neurons. Note, however, the prediction being tested is overly strong given the data of Lei et al. (2004). That study indicated that striato-GPe neurons receive significant IT-type input, as does our more recent size frequency curve-fitting approach presented here. Thus, while it is valuable to demonstrate that striato-GPe neurons can spike in response to IT-type input, the findings of Ballion et al. (2008) are not inconsistent with the idea that IT-type input preferentially targets striato-GPI/SNr neurons and PT-type input preferentially targets striato-GPe neurons. It should be noted that in a prior study in which they assessed direct and indirect pathway striatal neuron responses to the first of a 100-ms pair of stimulus pulses to ipsilateral cortex, indirect pathway striatal neurons responded significantly more rapidly than did direct pathway striatal neurons (Mallet et al., 2006), thus suggesting that PT input does preferentially target indirect pathway striatal neurons.

The work of Ballion et al. (2008) and Mallet et al. (2006), however, raises the issue of the relative abundance of the IT-type and PT-type inputs to the striatum. The data of Jinnai and Matsuda (1979) suggests that about $40 \%$ of the overall cortical input to dorsolateral striatum from motor and sensory cortex is PT-type. This interpretation is consistent with our VGLUT1 immunolabeling for rats noted above. Given their preferential input to indirect pathway neurons, a lesser PT-type input to striatum in rodents would be consistent with the sparser dendritic trees of indirect pathway type striatal projection neurons (Gertler et al., 2008). More detailed studies are needed to determine if this is also the case in primates. PT-type neurons projecting to the pons are present, however, throughout cortex, although the extent of their overall projection to striatum and the nature of the signal that they convey from non-motor or non-somatosensory cortices to striatum is uncertain. Genes have been identified that are uniquely expressed by either PT-type or IT-type neurons, and mice have been engineered that express green fluorescent protein (EGFP) in one or the other of these neuron types (Gong et al., 2007; Molyneaux et al., 2007). Such mice will be useful for assessing the relative abundances of the PT and IT inputs to the entire striatum.

\section{FUNCTIONAL CONSIDERATIONS}

The finding of a differential cortical input to striatal projection neurons may have implications for understanding how the cortical input contributes to the role of the direct and indirect pathway striatal projection neurons in motor control (Figure 9). In the case of direct pathway striatal neurons, convergence of IT-type input from diverse cortical areas providing information on movement planning, body position and the environment, and reward-prediction-related information from dopaminergic midbrain neurons onto individual striato-GPi/SNr neurons (Wilson, 1987; Cowan and Wilson, 1994; Zheng and Wilson, 2001), may provide the coherent input required to activate individual direct pathway neurons so that they facilitate movement. Because they are inherently less excitable and because their IT-type inputs are relatively ineffective at producing postsynaptic depolarization, more temporally correlated activation may be needed for direct pathway neurons than 


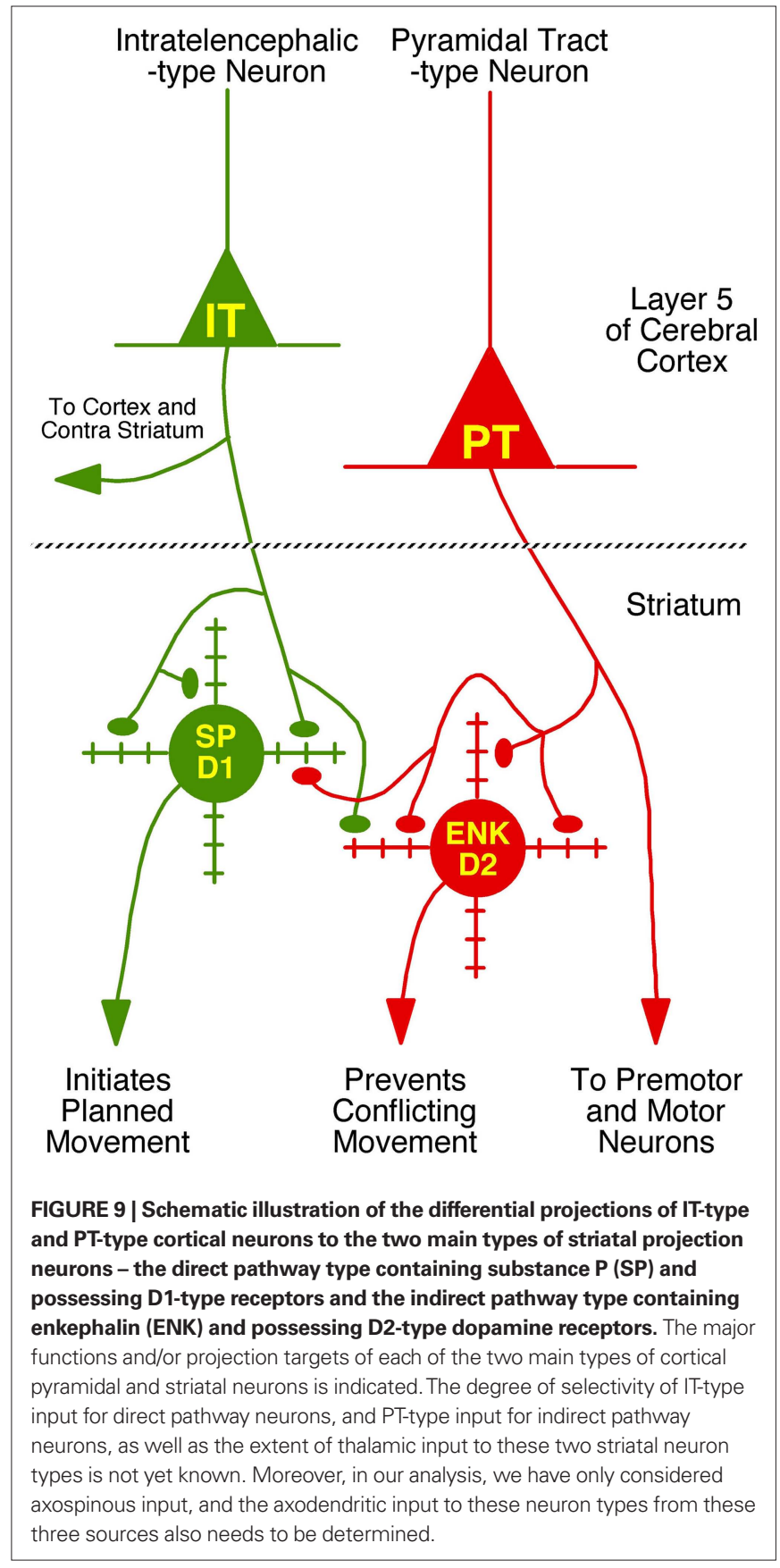

indirect pathway neurons and suited to the role of direct pathway neurons in motor sequence selection and initiation. Thalamic input related to attentional mechanisms may provide further excitatory drive needed to push the direct pathway neuron activation over the threshold for motor initiation (Smith et al., 2004).

Our findings also raise the possibility that striato-GPe neurons use an efference copy of movement commands provided by the PT-type input, which enables their role in suppressing movements that would otherwise conflict with ongoing selected movements. The somewhat more rapid conduction velocity of the PT-type input to striatum seems suited to such a role. The preferential PT-type input to striato-GPe neurons might also explain why movement- related activity exhibited by striatal projection neurons typically occurs during but not before movement (Jaeger et al., 1995; Mink, 1996) - most of the active striatal neurons are indirect pathway type neurons responding to collaterals of cortical pyramidal neuron axons. Nonetheless, the PT signal will reach premotor and motor neurons before the PT feedback signal reaches motor cortex via the striato-GPe-STN-GPi-motor thalamus loop, and thus be too late to prevent movements conflicting with the already initiated movement. This implies that the movement suppression caused by the PT signal to striato-GPe neurons may serve to suppress movements that would conflict with the next desired movement in the action sequence. The topographic organization of the PT-type input from somatosensory and somatomotor cortex to dorsolateral striatum may facilitate this role. Graybiel (2005) has also suggested the possibility that the PT-type input to ENK+ neurons may serve to terminate a specific act in the sequence initiated by $\mathrm{SP}+$ neurons.

\section{BASAL GANGLIA, MOTOR LEARNING AND THE DIFFERENTIAL CORTICAL INPUT TO STRIATUM}

Motor learning is a key part of the role of the basal ganglia (Graybiel, 2005). Considerable evidence supports the view that dopamine released from the intrastriatal terminals of substantia nigra both acts as a reward signal that sculpts the activity of striatal neurons during motor learning (Schultz et al., 2003; Graybiel, 2005), and instructs striatal neurons on the likelihood that a given circumstance can lead to reward (Ljungberg et al., 1992; Satoh et al., 2003; Morris et al., 2004; Tobler et al., 2005). The means by which motor learning occurs appears to be, in large part, changes in the efficacy of cortical synapses on striatal projection neurons. For example, to facilitate the onset of a specific motor routine, the efficacy of the cortical input to direct pathway neurons controlling that onset must be increased while the efficacy of the cortical input to the indirect pathway neurons suppressing that same routine must be reduced. Similarly, for those movements potentially conflicting with the desired routine, the efficacy of the cortical input to direct pathway neurons controlling the onset of such competing routines must be decreased, while the efficacy of the cortical input to the indirect pathway neurons suppressing those competing routines must be enhanced. The facts that D1-dependent LTP has been demonstrated in direct pathway neurons and D1 receptors are preferentially localized to direct pathway neurons suggest that the rewarding effects of dopamine on behavior are mediated via facilitation of IT-type inputs to direct pathway striatal neurons that control behaviors that obtain the reward (Kreitzer and Malenka, 2008; Shen et al., 2008). In this manner, the coincident activation of the convergent cortical inputs to the direct neurons mediating the rewarded behavior becomes more able to fire those neurons. This phenomenon may explain the emergence of striatal activity in response to a go cue during procedural learning (Ljungberg et al., 1992; Satoh et al., 2003; Morris et al., 2004; Tobler et al., 2005). The striatal activity in this sense reflects a motor go cue when the combination of exteroceptive and interoceptive circumstances are appropriate. The observation that dopamine depletion converts LTP to LTD in direct pathway neurons is consistent with the notion that absence of a dopaminergic reward signal to the IT-type inputs projecting to those striatal neurons initiating the unrewarded behaviors makes those synapses less likely to initiate the unrewarded response (Kreitzer and Malenka, 2008). 
If the indirect pathway neurons function to serve as a stop feedback signal to the PT-type neurons that provide them an efference copy of their discharge to motor or premotor neurons, then plasticity at the PT-type synapse would serve to modulate the stop signal. In the case of desirable behaviors, the stop signal might be inappropriate. Reward-mediated depression of the PT-type input would then help adjust the pyramidal neuron control of the movement so its duration is better suited to achieve a rewarded outcome. Conversely, PT-type neuronal activity that brings about unrewarded behaviors would send a corollary discharge to indirect pathway neurons that becomes strengthened by the absence of dopamine reward, leading to a heightened tendency of the indirect pathway neurons to suppress these same PT-type cortical neurons, and reduce likelihood of the occurrence of the unsuccessful behavior. Because of the efficacy of this synaptic contact and the high responsivity of indirect pathway neurons to their cortical input, basal firing of the PT input that is subthreshold for movement may be adequate to maintain sufficient indirect pathway neuron output to keep pyramidal tract neuron firing below movement threshold. This suggests that motor learning in basal ganglia may involve learning which movements to suppress and which not to suppress, and the PT-type input to striato-GPe neurons may thus be an important neural substrate by which the basal ganglia learns to refine motor sequences during procedural learning.

\section{REFERENCES}

Albin, R. L., Young, A. B., and Penney, J. B. (1989). The functional anatomy of basal ganglia disorders. Trends Neurosci. 12, 366-375.

Alloway, K. D., Mutic, J. J., and Hoover, J. E. (1998). Divergent corticostriatal projections from a single cortical column in the somatosensory cortex of rats. Brain Res. 785, 341-346.

Arbuthnott, G. W., and Wickens, J. (2006). Space, time and dopamine. Trends Neurosci. 30, 62-69.

Arikuni, T., and Kubota, K. (1986). The organization of prefrontocaudate projections and their laminar origin in the macaque monkey: a retrograde study using HRP-gel. J. Comp. Neurol. 244, 492-510.

Ballion, B., Mallet, N., Bezard, E., Lanciego, J. L., and Gonon, F. (2008). Intratelencephalic corticostriatal neurons equally excite striatonigral and striatopallidal neurons and their discharge activity is selectively reduced in experimental parkinsonism. Eur. J. Neurosci. 27, 2313-2321.

Bauswein, E., Fromm, C., and Preuss, A. (1989). Corticostriatal cells in comparison with pyramidal tract neurons: contrasting properties in the behaving monkey. Brain Res. 493, 198-203.

Beloozerova, I. N., Sirota, M. G., Swadlow, H. A., Orlovsky, G. N., Popova, L. B., and Deliagina, T. G. (2003). Activity of different classes of neurons of the motor cortex during postural corrections. J. Neurosci. 23, 7844-7853.
Berretta, S., Parthasarathy, H. B., and Graybiel, A. M. (1997). Local release of GABAergic inhibition in the motor cortex induces immediate-early gene expression in indirect pathway neurons of the striatum. J. Neurosci. 17, 4752-4763.

Brown, L.L.,Smith,D.M., and Goldbloom, L. M. (1998). Organizing principles of cortical integration in the rat neostriatum: corticostriate map of the body surface is an ordered lattice of curved laminae and radial points. J. Comp. Neurol. 392, 468-488.

Cepeda, C., André, V.M., Yamazaki, I., Wu, N., Kleiman-Weiner, M., and Levine, M.S. (2008). Differential electrophysiological properties of dopamine D1 and D2 receptor-containing striatal medium-sized spiny neurons. Eur. J. Neurosci. 27, 671-682.

Chung, J. W., Hassler, R., and Wagner, A. (1977). Degeneration of two of nine types of synapses in putamen after centre median coagulation in the cat. Exp. Brain Res. 28, 345-361.

Cowan, R. L., and Wilson, C. J. (1994). Spontaneous firing patterns and axonal projections of single corticostriatal neurons in the rat medial agranular cortex. J. Neurophysiol. 71, 17-32.

DeLong, M. (1990). Primate models of movement disorders of basal ganglia origin. Trends Neurosci. 13, 281-285.

Deng, Y. D., Lei, W. L., and Reiner, A. (2006). Differential localization in rats of D1 and D2 dopamine receptors on striatal projection neuron types

Loss of basal dopamine levels due to dopaminergic neuron degeneration in Parkinson's disease (PD) results in loss of basal dopamine inhibition of indirect pathway neurons and basal dopamine excitation of direct pathway neurons (Kreitzer and Malenka, 2008). As a consequence, the basal ganglia output is abnormal and yields increased movement suppression and decreased movement initiation. The loss of striatal dopamine, however, impairs corticostriatal plasticity as well. LTD at the PT-type inputs to indirect pathway neurons may be diminished, further contributing to the excess inhibition of movement in PD. Similarly, loss of dopamine may impair LTP at IT-type input to direct pathway neurons, and impair the corticostriatal facilitation that underlies new motor learning. Thus, impairments in both learning and carrying out motor routines may be impaired in PD (Arbuthnott and Wickens, 2006).

\section{ACKNOWLEDGMENTS}

We thank our various collaborators over the years who have made much of the research presented here possible, notably Drs Nobel Del Mar, Yun Jiao, and Antonio Laverghetta. Any of our work summarized here was supported by NS19620 and NS57722 (Anton Reiner), and the National Science Foundation of China grants 30770679, 31070941, 20831006, 30570572 (Wanlong Lei).

identified by retrograde labeling. J. Chem. Neuroanat. 32, 101-116.

Deng, Y. P., Hart, N. M., and Reiner, A. (2010). Relative abundance and striatal projection neuron targeting of IT-type and PT-type corticostriatal neurons in rodents and primates. Soc Neurosci. Abs., Abst \# 686.1.

Ding, J., Peterson, J. D., and Surmeier, D. J. (2008). Corticostriatal and thalamostriatal synapses have distinctive properties. J. Neurosci. 28, 6483-6492.

Donoghue, J. P., and Herkenham, M. (1986). Neostriatal projections from individual cortical fields conform to histochemically distinct striatal compartments in the rat. Brain Res. 12, 397-403.

Donoghue, J. P., and Kitai, S. T. (1981). A collateral pathway to the neostriatum from corticofugal neurons of the rat sensory-motor cortex: an intracellular HRP study. J. Comp. Neurol. 210, 1-13.

Flaherty,A.W., and Graybiel,A.M. (1993). Two input systems for body representations in the primate striatal matrix: experimental evidence in the squirrel monkey. J. Neurosci. 13, 1120-1137.

Fremeau, R. T., Troyer, M. D., Pahner, I. Nygaard, G. O., Tran, C. H., Reiner, R. J., Bellocchio, E. E., Fortin, D., Storm-Mathisen, J., and Edwards, R. H. (2001). The expression of vesicular glutamate transporters defines two classes of excitatory synapse. Neuron 31, 247-260.

Fremeau, R. T., Voglmaier, S., Seal, R. P., and Edwards, R. H. (2004). VGLUTs define subsets of excitatory neurons and suggest novel roles for glutamate. Trends Neurosci. 27, 98-103.

Fujiyama, F., Kuramoto, E., Okamoto, K., Hioki,H., Furuta, T.,Zhou,L., Nomura, S., and Kaneko, T. (2004). Presynaptic localization of an AMPA-type glutamate receptor in corticostriatal and thalamostriatal axon terminals. Eur. J. Neurosci. 20, 3322-3330.

Gerfen, C. R. (1984). The neostriatal mosaic: compartmentalization of corticostriatal input and striatonigral output systems. Nature 311, 461-464.

Gerfen, C. R. (1989). The neostriatal mosaic: striatal patch-matrix organization is related to cortical lamination. Science 246, 385-388.

Gerfen, C. R. (1992). The neostriatal mosaic: multiple levels of compartmental organization. Trends Neursci. 15, 133-139.

Gerfen, C. R., and Wilson, C. J. (1996). "The basal ganglia," in Handbook of Chemical Anatomy. Integrated System of the CNS. Part III, eds L. W. Swanson, A. Bjorklund and T. Hokfelt, (Amsterdam: Elsevier), 360-466.

Gertler, T. S., Chan, C. S., and Surmeier, D. J. (2008). Dichotomous anatomical properties of adult striatal medium spiny neurons. J. Neurosci. 28, 10814-10824.

Goldman-Rakic, P., and Selemon, L. D. (1986).“Topography of corticostriatal projections in nonhuman primates and implications for functional parcellation of the neostriatum," in Cerebral Cortex, Vol. 5, eds E. G. Jones and A. 
Peters (New York, NY: Plenum Press), 447-466.

Gong, S., Doughty, M., Harbaugh, C. R., Cummins, A., Hatten, M. E., Heintz, N., and Gerfen, C. R. (2007). Targeting cre-recombinase to specific neuron populations with bacterial artificial chromosome constructs. J. Neurosci. 2, 9817-9823.

Graybiel, A. M. (2005). The basal ganglia: learning new tricks and loving it. Curr. Opin. Neurobiol. 15, 638-644.

Hedreen, J.C. (1977). Corticostriatal cells identified by the peroxidase method. Neurosci. Lett. 4, 1-7.

Hedreen, J. C., and McGrath, S. (1977). Observations on labeling of neuronal cell bodies, axons and terminals after injection of horseradish peroxidase into rat brain. J. Comp. Neurol. 176, 225-246.

Herzog, E., Bellenchi, G. C., Gras, C., Bernard, V., Ravassard, P., Bedet, C., Gasnier, B., Giros, B., and El Mestikawy, S. (2001). The existence of a second vesicular glutamate transporter specifies subpopulations of glutamatergic neurons. J. Neurosci. 21, 1-6.

Hoffer, Z. S., and Alloway, K. D. (2001). Organization of corticostriatal projections from the vibrissal representations in the primary motor and somatosensory cortical areas of rodents. J. Comp. Neurol. 439, 87-103.

Jaeger, D. J., Gilman, S., and Aldridge, J. W. (1995). Neuronal activity in the striatum and pallidum of primates related to the execution of externally cued reaching movements. Brain Res. 694, 111-127.

Jinnai, K., and Matsuda, Y.(1979). Neurons of the motor cortex projecting commonly on the caudate nucleus and the lower brainstem in the cat. Neurosci. Lett. 13, 121-126.

Jones, E. G., Coulter, J.D., Burton, H., and Porter, R. (1977). Cells of origin and terminal distribution of corticostriatal fibers arising in the sensory-motor cortex of monkeys. J. Comp. Neurol. $173,53-80$.

Jones, E. G., and Wise, S. P. (1977). Size, laminar and columnar distribution of efferent cells in the sensory-motor cortex of monkeys. J. Comp. Neurol. 175, 391-438.

Kawaguchi, Y., Wilson, C. J., and Emson, P. C. (1990). Projection subtypes of rat neostriatal matrix cells revealed by intracellular injection of biocytin. J. Neurosci. 10, 3421-3438.

Kemp, J. M., and Powell, T. P. S. (1970). The cortico-striate projection in the monkey. Brain 93, 525-546.

Kincaid, A. E., and Wilson, C. J. (1996). Corticostriatal innervation of the patch and matrix in the rat neostriatum. J. Comp. Neurol. 374, 578-592.
Kitai, S. T., Kocsis, J. D., and Wood, J. (1976). Origin and characteristics of the cortico-caudate afferents: an anatomical and electrophysiological study. Brain Res. 118, 137-141.

Kreitzer,A.C., and Malenka, R.C. (2007). Endocannabinoid-mediated rescue of striatal LTD and motor deficits in Parkinson's disease models. Nature 445, 643-647.

Kreitzer, A.C., and Malenka, R. C. (2008) Striatal plasticity and basal ganglia circuit function. Neuron 60, 543-554.

Lacey, C. J., Bolam, J. P., and Magill, P. J. (2007). Novel and distinct operational principles of intralaminar thalamic neurons and their striatal projections. J. Neurosci. 27, 4374-4384.

Landry, P., Wilson, C. J., and Kitai, S. T. (1984). Morphological and electrophysiological characteristics of pyramidal tract neurons in the rat. Exp. Brain Res. 57, 177-190.

Lei, W. L., Jiao, Y., Del Mar, N., and Reiner, A. (2004). Evidence for differential cortical input to direct pathway versus indirect pathway striatal projection neurons in rats. J. Neurosci. 24 , 8289-8299.

Levesque, M., Charara, A., Gagnon, S., Parent, A., and Descenes, M. (1996a). Corticostriatal projections from layer $\mathrm{V}$ cells in rat are collaterals of longrange corticofugal axons. Brain. Res. 709, 311-315.

Levesque, M., Gagnon, S., Parent, A., and Descenes, M. (1996b). Axonal arborizations of corticostriatal and corticothalamic fibers arising from the second somatosensory area in the rat. Cereb. Cortex 6, 759-770.

Levesque, M., and Parent, A. (1998). Axonal arborization of corticostriatal and corticothalamic fibers arising from prelimbic cortex in the rat. Cereb. Cortex 8, 602-613.

Ljungberg, T., Apicella, P., and Schultz, W. (1992). Responses of monkey dopamine neurons during learning of behavioral reactions. J. Neurophysiol. $67,145-163$.

Mallet, N., Ballion, B., Le Moine, C., and Gonon, F. (2006). Cortical inputs and GABA interneurons imbalance projection neurons in the striatum of Parkinsonian rats. J. Neurosci. 26, 3875-3884.

McGeorge, A. J., and Faull, R. L. M. (1989). The organization of the projection from the cerebral cortex to the striatum in the rat. Neuroscience 29 , 503-537.

Mink, J. W. (1996). The basal ganglia: focussed selection and inhibition of competing motor programs. Prog. Neurobiol. 50, 381-425.

Molnar, Z., and Cheung, A. F. P. (2006). Towards the classification of subpopu- lations of layer $\mathrm{V}$ pyramidal projection neurons. Neurosci. Res. 55, 105-115.

Molyneaux, B. J., Arlotta, P., Menezes, J. R. L., and Macklis, J. D. (2007) Neuronal subtype specification in the cerebral cortex. Nat. Rev. Neurosci. 8 , 427-437.

Morris, G., Arkadir, D., Nevet, A., Vaadia, E., and Bergman, H. (2004). Coincident but distinct messages of midbrain dopamine and striatal tonically active neurons. Neuron 43 133-143.

Oka, H. (1980). Organization of the cortico-caudate projections: a horseradish peroxidase study in the cat. Exp. Brain Res. 40, 203-208.

Parent, M., and Parent, A. (2006). Singleaxon tracing study of corticostriatal projections arising from primary motor cortex in primates. J. Comp Neurol. 496, 202-213.

Parthasarathy, H. B., and Graybiel, A. M. (1997). Cortically driven immediate early gene expression reflects modular influence of sensorimotor cortex on identified striatal neurons in the squirrel monkey. J. Neurosci. 17, 2477-2491.

Raju, D.V., Shah, D. J., Wright, T.M., Hall, R.A., and Smith, Y. (2006). Differential synaptology of vGluT2-containing thalamostriatal afferents between the patch and matrix compartments in rats. J. Comp. Neurol. 499, 231-243.

Ramon y Cajal, S. (1911). Histologie du Systeme Nerveux de l'Homme et des Vertebres. Paris: Maloine.

Reiner,A.,Jiao, Y., Del Mar, N.,Laverghetta, A. V., and Lei, W. L. (2003). Differential morphology of pyramidal-tract type and intratelencephalically-projecting type corticostriatal neurons and their intrastriatal terminals in rats. J. Comp. Neurol. 457, 420-440.

Reiner, A., Lei, W. L., and Deng, Y. P. (2008). Evidence for two types of cortical projections to striatum in rhesus monkeys. Soc. Neurosci. Abs. Abstract \# 670.5

Royce, G. J. (1982). Laminar origin of cortical neurons which project upon the caudate nucleus: a horseradish peroxidase investigation in the cat. $J$. Comp. Neurol. 205, 8-29.

Rudkin, T. M., and Sadikot, A. F. (1999). Thalamic input to parvalbuminimmunoreactive GABAergic interneurons: organization in normal striatum and effect of neonatal decortication. Neuroscience 88, 1165-1175.

Satoh, T., Nakai, S., Sato, T., and Kimura, M. (2003). Correlated coding of motivation and outcome of decision by dopamine neurons. J. Neurosci. 23 , 9913-9923.

Schultz,W., Tremblay, L., and Hollerman, J. R. (2003).Changes in behavior-related neuronal activity in the striatum during learning. Trends Neurosci. 26, 321-328.

Schwab, M., Agid, Y., Glowinski, L., and Thoenen, H. (1977). Retrograde axonal transport of I-tetanus toxin as a tool for tracing fiber connections in the central nervous system: connections of the rostral part of the rat neostriatum. Brain Res. 126, 211-244.

Selemon, L. D., and Goldman-Rakic, P. S. (1985). Longitudinal topography and interdigitation of corticostriatal projections in the rhesus monkey. $J$ Neurosci. 5, 776-794.

Shen, W., Flajolet, M., Greengard, P., and Surmeier, D. J. (2008). Dichotomous dopaminergic control of striatal synaptic plasticity. Science 321, 848-851.

Sidibe, M., and Smith,Y. (1999). Thalamic inputs to striatal interneurons in monkeys: synaptic organization and co-localization of calcium binding proteins. Neuroscience 89, 1189-1208.

Smith, Y., Raju, D.V., Pare, J. F., and Sidibe, M. (2004). The thalamostriatal system: a highly specific network of the basal ganglia circuitry. Trends Neurosci. 27, 520-527.

Surmeier, D. J., Song, W. J., and Yan, Z. (1996). Coordinated expression of dopamine receptors in neostriatal medium spiny neurons. J. Neurosci. $16,6579-6591$.

Tanaka, D. (1987). Differential laminar distribution of corticostriatal neuron in the prefrontal and pericruciate gyri of the dog. J. Neurosci. 7, 4095-4106.

Tanaka, D., Gorska, T., and Dutkiewicz, K. (1981). Corticostriate projections from the primary motor cortex in the dog. Brain Res. 209, 287-303.

Tepper, J. M., Koos, T., and Wilson, C. J. (2004). GABAergic microcircuits in the neostriatum. Trends Neurosci. 27, 662-669.

Tobler, P. N., Fiorillo, C. D., and Schultz, W. (2005). Adaptive coding of reward value by dopamine neurons. Science 307, 1642-1645.

Turner, R. S., and DeLong, M. R. (2000). Corticostriatal activity in primary motor cortex of the macaque. $J$. Neurosci. 20, 7096-7108.

Uhl, G. R., Navia, B., and Douglas, J. (1988). Differential expression of preproenkephalin and preprodynorphin mRNAs in striatal neurons: high levels of preproenkephalin expression depend on cerebral cortical afferents. J. Neurosci. 8, 4755-4764.

Varoqui, H., Schäfer, M. K. H., Zhu, H., Weihe, E., and Erickson, J. D. (2002) Identification of the differentiationassociated $\mathrm{Na}+$ /PI transporter as a novel vesicular glutamate transporter expressed in a distinct set of 
glutamatergic synapses. J. Neurosci. 22, 142-155.

Veening, J.G., Cornelissen, F.M., and Lieven, P. A. J. M. (1980). The topical organization of the afferent to the caudatoputamen of the rat.A horseradish peroxidase study. Neuroscience 5, 5253-5268.

Walsh, J. P. (1993). Depression of excitatory synaptic input in rat striatal neurons. Brain Res. 608, 123-128.

Wang, H., and Pickel, V. M. (1998). Dendritic spines containing mu-opioid receptors in rat striatal patches receive asymmetric synapses from prefrontal corticostriatal afferents. J. Comp. Neurol. 396, 223-237.

Wang, H. B., Laverghetta, A. V., Foehring, R., Deng, Y. P., Sun, Z., Yamamoto, K., Lei, W. L., Jiao, Y., and Reiner, A. (2006). Single-cell RT-PCR, in situ hybridization histochemical, and immunohistochemical studies of substance $P$ and enkephalin co-occurrence in striatal projection neurons in rats. J. Chem. Neuroanat. 31, 178-199.

Wilson, C. J. (1986). Postsynaptic potentials evoked in spiny neostriatal projection neurons by stimulation of ipsilateral and contralateral neocortex. Brain Res. 367, 201-213.

Wilson, C. J. (1987). Morphology and synaptic connections of crossed corticostriatal neurons in the rat. J. Comp. Neurol. 263, 567-580.

Wilson, C. J., Chang, H. T., and Kitai, S. T. (1982). Origins of postsynaptic potentials evoked in identified neostriatal neurons by stimulation in substantia nigra. Exp. Brain. Res. 45, 157-167.

Wise, S. P., and Jones, E. G. (1977). Cells of origin and terminal distribution of descending projections of the rat somatic sensory cortex. J. Comp. Neurol. 175, 129-158.

Wright, A. K., Norrie, L., Ingham, C. A., Hutton, A. M., and Arbuthnott, G. W.
(1999). Double anterograde tracing of the outputs from adjacent "barrel columns" of rat somatosensory cortex neostriatal projection patterns and terminal ultrastructure. Neuroscience $88,119-133$.

Wright, A. K., Ramanthan, S., and Arbuthnott, G. W. (2001) Identification of the source of the bilateral projection from cortex to somatosensory neostriatum and an exploration of its physiological actions. Neuroscience 103, 87-96.

Wu, Y., Richard, S., and Parent, A. (2000). The organization of the striatal output system: a single-cell juxtacellular labeling study in the rat. Neurosci. Res. $38,49-62$.

Zheng, T., and Wilson, C. J. (2001). Corticostriatal combinatorics: the implications of corticostriatal axonal arborizations. J. Neurophysiol. 87, 1007-1017.
Conflict of Interest Statement: The authors declare that the research was conducted in the absence of any commercial or financial relationships that could be construed as a potential conflict of interest

Received: 23 June 2010; accepted: 29 September 2010; published online: 25 October 2010.

Citation: Reiner A, Hart NM, Lei W and Deng Y (2010) Corticostriatal projection neurons - dichotomous types and dichotomous functions. Front. Neuroanat. 4:142. doi: 10.3389/fnana.2010.00142

Copyright () 2010 Reiner, Hart, Lei and Deng. This is an open-access article subject to an exclusive license agreement between the authors and the Frontiers Research Foundation, which permits unrestricted use, distribution, and reproduction in any medium, provided the original authors and source are credited. 